\title{
UNA ESCRITURA DE COMPROMISO DE OTORGAR LA HALISSA
}

JOSÉ LUIS LACAVE

CSIC. Madrid

Creo que uno de los rasgos que mejor definen la personalidad del Prof. Díaz Esteban, mi buen amigo y compañero de tantos años, es su inmensa curiosidad científica, que lo ha llevado a atender a múltiples campos de los estudios hebraicos y judaicos. Por ello, a la hora de contribuir al merecido homenaje que se le brinda en este volumen, me ha parecido oportuno dar a conocer un documento curioso. Curioso, no sólo porque es el único documento hebreo de este tipo que se ha hallado en España hasta ahora, sino también porque esta clase de documentos debió de ser muy rara entre los judíos españoles.

Sabido es que el cumplimiento del precepto bíblico del levirato (Deut 25,5-10) causaba innumerables problemas en la vida cotidiana de los judíos medievales, y que se utilizaron diversos procedimientos para solucionar esos problemas o incluso para atajarlos de antemano. Uno de esos procedimientos es lo que tenemos en el documento hebreo que ahora publico.

No está de más que recordemos aquí en qué consiste la ley del levirato. Si una mujer queda viuda sin hijos, el hermano del marido difunto, el levir (yabam), ha de casarse con la viuda (yěbamâ). En el caso de que rehusare hacerlo, ha de llevar a cabo la ceremonia de la halissa, por la cual la yěbamá queda libre para casarse con quien quiera. Esto supone que una mujer en tal situación, al quedar viuda sin hijos, para poder casarse de nuevo y para poder cobrar su $k e ̌ t u b b a \hat{a}$ de la hacienda de su difunto marido, está necesitada (zěqûqâ) o bien de casarse con el yabam, o bien de que éste cumpla la hallsá.

Ahora bien, los inconvenientes para que se lleve a cabo el matrimonio levirático (yibbum) pueden ser muchos. Diferencia de edad entre el yabam y la yěbamâ, una enfermedad incurable, etc., etc. Por esos muchos inconvenientes era habitual que la familia de 
la yěbamâ tratara de conseguir del yabam que cumpliera la halisâ. Pero el problema grave se planteaba cuando el yabam rehusaba hacerlo "por razones inconfesables", por ejemplo, porque pedía algo a cambio. Con esa conducta del yabam, la viuda, la yěbamâ, no sólo no podía casarse de nuevo libremente, sino que tampoco podía recuperar su kètûbbâ de la hacienda de su difunto marido. Algún caso de este tipo ocurrido en España recoge I. Baer en su colección documental '.

Uno de los procedimientos para evitar los problemas que el posible futuro caso de levirato pudiera causar consistía en que en el momento del matrimonio, el hermano del novio, es decir, el posible futuro yabam, firmara un documento comprometiéndose a otorgar la halisâa a la novia en el caso de que quedara viuda sin hijos. Al parecer, este procedimiento no fue apenas utilizado en España, con la posible excepción de Cataluña, probablemente porque en el judaísmo arabizado de los reinos hispánicos los rabinos concedían prioridad a la obligación de llevar a cabo el matrimonio levirático (yibbûm) sobre la de cumplir la hallsa ${ }^{2}$. En cambio, en el judaísmo centroeuropeo, donde los rabinos daban prioridad a la obligación de cumplir la halissâ, fue un procedimiento muy extendido.

El documento que aquí traemos, por el cual un posible futuro yabam se compromete, al tiempo de la boda de su hermano, a otorgar la halisâ, es, no obstante, de Tudela, en el reino de Navarra, cuya aljama sabemos que se regía según la opinión de Maimónides en las normas rabinicas ${ }^{3}$. Pero ocurre que el novio de aquella boda y su familia - y por tanto, el futuro yabam - son de origen francés como lo revelan sus nombres (el novio Natán de Narbona; su padre, Yacaqob de Narbona; y el futuro yabam, Mošeh de Narbona), y seguramente seguirían las normas rabínicas según la tradición centroeuropea.

El documento se halla inserto en un apéndice a una kĕtûbbâ, del cual ya di una primera noticia en un artículo anterior ${ }^{4}$, y que se

${ }^{1}$ F. BAER, Die Juden im Christlichen Spanien, vol I, Berlin 1929, $\mathrm{n}^{2} 449$. V. también Y. BAER, Historia de los judíos en la España cristiana, Madrid 1981, vol. II, pág. 413.

${ }^{2}$ Maimónides, Yad, Yibbum 1,2. Véase además Y. BAER, Historia, vol. I, pág. 300.

${ }^{3}$ Así se expresaba claramente en las taqqanót de dicha aljama de 1305 . V. F. BAER, Die Juden, vol. I, $\mathrm{n}^{\circ} 586$.

4 J. L. LACAVE, "Importante hallazgo de documentos hebreos en Tudela», Sefarad XLIII (1983) 169-179, doc. $\mathrm{n}^{2} 5$. 
conserva en el Archivo Municipal de la citada ciudad navarra. La

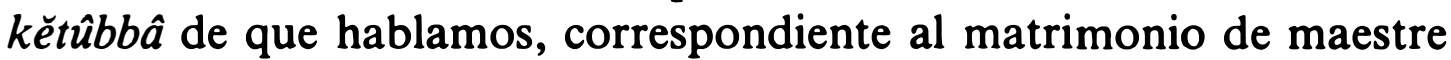
Natán de Narbona con Dueña, hija de Šěmû̉el Alašbilí (el Sevillano) ${ }^{5}$, se había escriturado en Borja (reino de Aragón), lugar de residencia de la novia, el día 10 de adar II del año 5242 (1 de marzo de 1482). Y dos días después, el 12, se escrituraba en Tudela (reino de Navarra, pero cerca de Borja), lugar de residencia del novio y su familia, el mencionado apéndice que incluía los siguientes documentos: 1) la mattanâ lẹhû́ que el novio daba a la novia; 2) documento por el que los padres del novio, maestre Yacaqob de Narbona y doña Aljoer (Perla) junto con su hijo, y por tanto hermano del novio, Mošeh de Narbona, se constituyen garantes del cumplimiento de la kétûbbâ por parte del novio Natán, y del pago de las sumas a que hubiere lugar en su caso; y 3) el documento que ahora nos interesa.

Este documento de compromiso consiste en lo siguiente: Mošeh de Narbona, para el caso de que Dueña, esposa de su hermano Natán, se quedara viuda sin hijos, se compromete con su persona y bienes a darle a la citada Dueña un documento de halisa rabínicamente legal y a llevar a cabo la ceremonia de la halisâ; ello en un plazo de 30 días a partir del momento en que ella o sus representantes se lo reclamen, sin poner ninguna traba y sin pedir nada a cambio.

A continuación Mošeh se compromete a pagar un multa de cien florines de oro, de curso en Aragón, en el caso de que pusiera alguna traba para cumplir su compromiso o no lo cumpliera en el plazo mencionado; además se compromete a pagar los daños y perjuicios que le pudieran sobrevenir a Dueña a causa de su incumplimiento.

Luego Mošeh acepta que Dueña puede presentar una demanda contra él ante cualquier tribunal, y que los jueces hagan con él lo que sea menester en tanto no cumpla su compromiso. Para reforzar más el compromiso y los derechos de Dueña, Mošeh jura por la Torá cumplir todo lo escrito y no transgredir ninguno de sus puntos. Y concede a Dueña que en la interpretación del documento -en una hipotética reclamación futura - sea válido lo que ella o sus representantes digan. Vienen luego las fórmulas de garantía, etc.,

${ }^{5}$ Este "apellido", con diversas grafias, aparece con frecuencia en los documentos de Navarra y Aragón. 
con que terminan los documentos legales rabínicos y a continuación se fecha el documento, se consignan las correciones habidas en la escritura y firman los testigos.

Para terminar, haremos mención brevemente de algún dato que revela la situación histórica en que se redacta el documento, por otra parte ya conocida. La multa se ha de pagar con dinero de curso legal en Aragón, a pesar de que quien la habría de pagar residía en Navarra. No hay duda de que usar una $u$ otra moneda era cosa fácil, sin que contaran gran cosa las fronteras, y como la familia de la novia reside en Aragón, pide que se le pague con aquella moneda.

Como era habitual en los reinos hispánicos, una multa, aunque fuera como aquí por un pleito civil judío y sólo entre judíos, había de pagarse la mitad para el rey y la mitad para la parte demandante. Y para evitar interpretaciones distorsionadoras, se dice que la multa se pagará al rey o a la reina, al gobernante o al funcionario que lo reclame, aunque la ley dictaba que se pagaría al tesoro real. Por la misma razón, la persona que adquiere el compromiso se somete a la autoridad de cualquier tribunal, judío o no. De ese modo se evitaba que, cuando llegara el caso, alegara que no era lícito rabínicamente, por tratarse de un pleito entre judíos, acudir a un tribunal gentil, con la acusación de malsindad al fondo.

\section{EDICIÓN DEL DOCUMENTO}

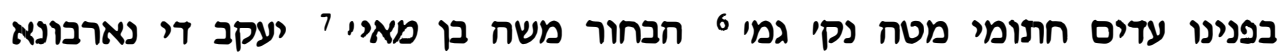

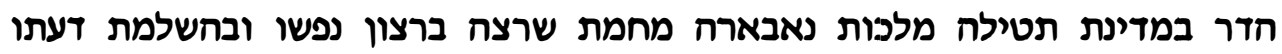

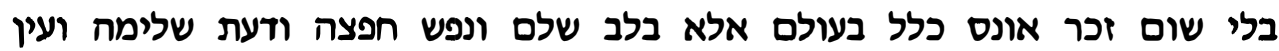

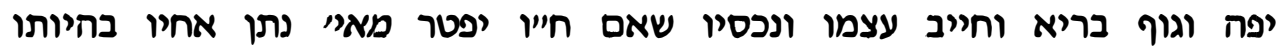

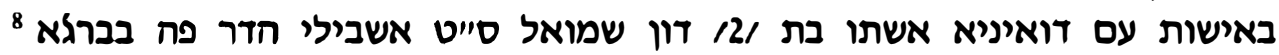

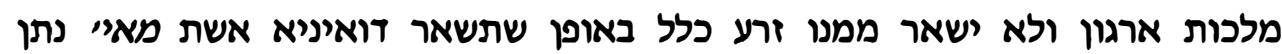

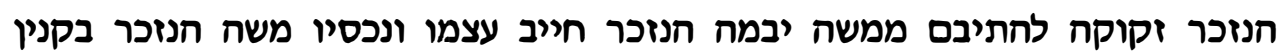

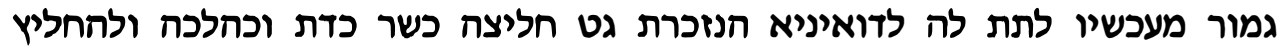

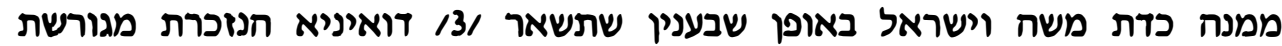

\footnotetext{
6 נטל קנין גמור 6.

7 מאישטר, maestre.

${ }^{8}$ La primera 2 , encima de la línea. Se escritura y firman los testigos en Tudela, luego la palabra פ está ahí erróneamente. Sin duda, el escribano se dejó llevar por el tenor habitual.
} 


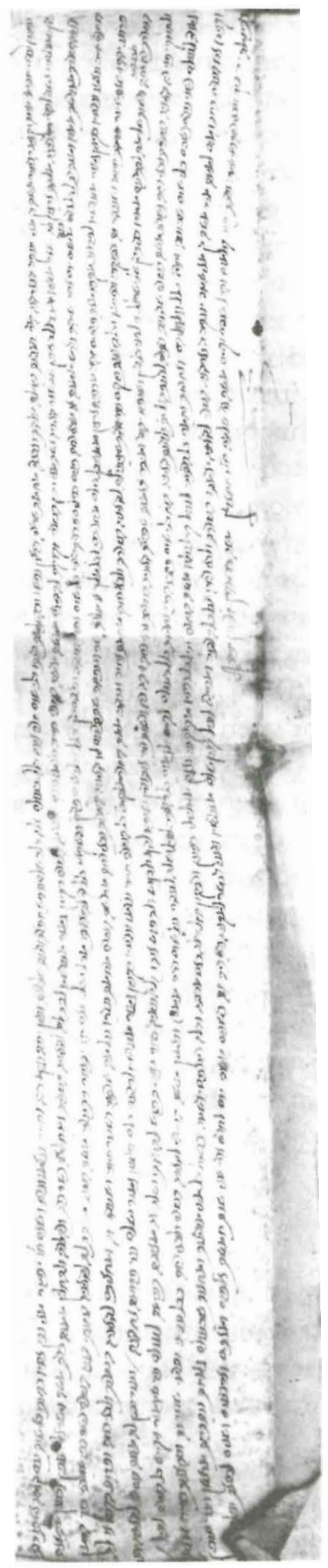




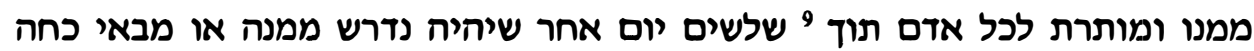

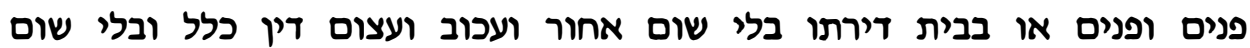

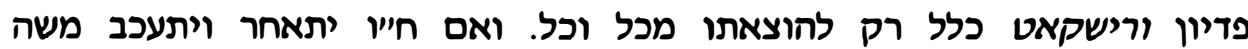

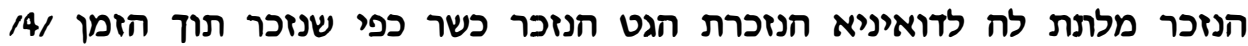

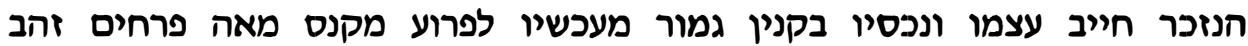

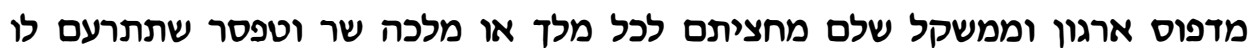

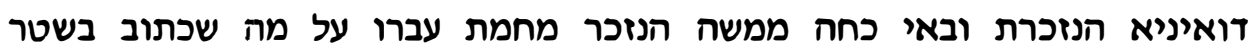

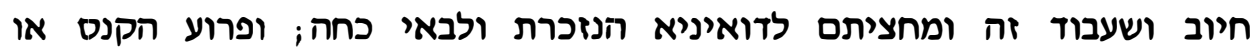

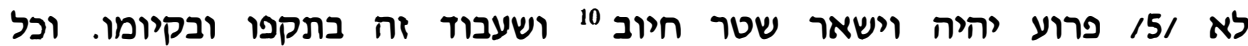

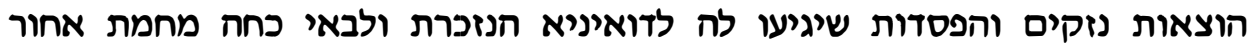

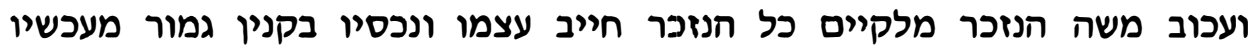

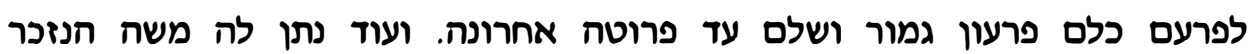

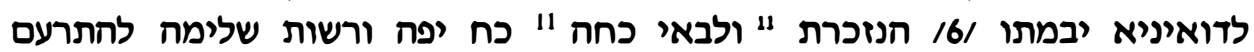

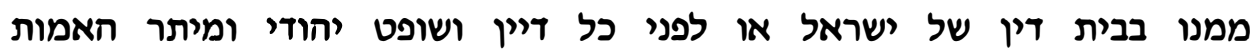

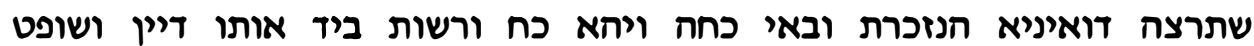

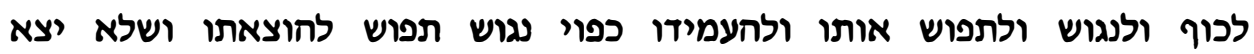

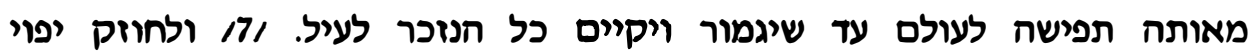

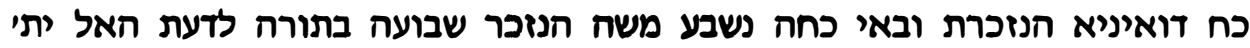

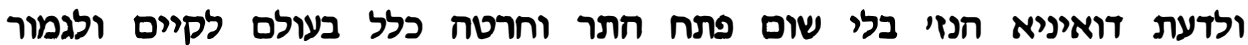

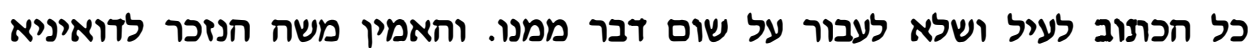

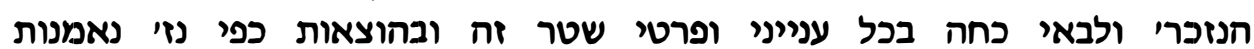

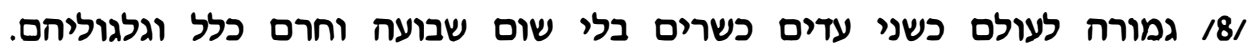

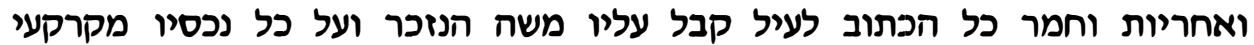

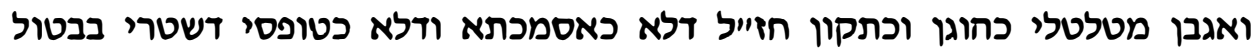

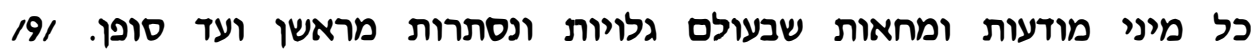

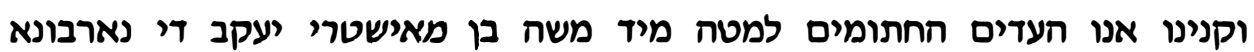

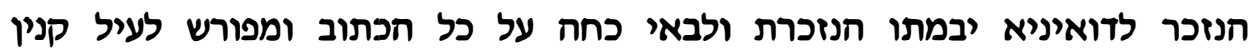

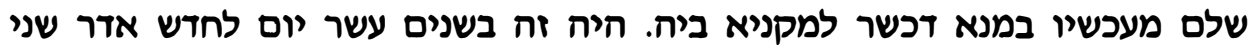

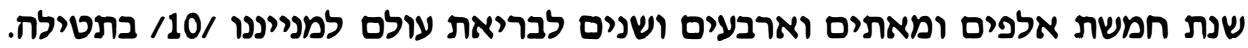

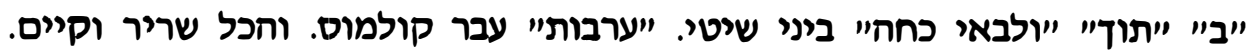
משה ברי שלמה סי"ט חסאני. משה ברי אחרן זיוני יניל בן סידה.

\section{VERSIÓN ESPAÑOLA}

Ante nosotros, los testigos firmantes abajo, recibió qinyán íntegro el joven Mošeh, hijo de maestre Ya`aqob de Narbona, residente en la ciudad de Tudela, del reino de Navarra, por cuanto que quiere voluntariamente y

9 Esa palabra, encima de la línea.

10 Antes de esa palabra pone, tachado, ערבות.

"Esas dos palabras, encima de la línea. 
con plena consciencia, sin ningún género de coacción en absoluto, sino de todo corazón, voluntariamente y con plena consciencia, de buen grado y en perfecto estado de salud, obligarse con su persona y bienes a que si, Dios no lo quiera, falleciese maestre Natán, su hermano, estando en matrimonio con Dueña, su esposa, hija de $/ 2 /$ don Šěmû̉el, su fin sea para bien, Ašbilí, residente aquí ${ }^{12}$, en Borja, del reino de Aragón, y no quedara de él descendencia ninguna, de manera que quedara Dueña, esposa del citado maestre Natán, necesitada de casarse por la ley del levirato con Mošeh, su yabam mencionado, se obliga con su persona y bienes el citado Mošeh, con qinyán íntegro desde ahora, a darle a la citada Dueña un documento de halis $a$, apropiado, conforme a la prescripción y a la ley talmúdica, y a llevar a cabo la ceremonia de la halissa conforme a la ley de Moisés e Israel, de manera que quedara /3/ la citada Dueña repudiada por él y lícita para cualquier hombre, en el plazo de treinta días a partir del momento en que se le reclame por ella o por los representantes de ella, cara a cara o en su residencia, sin ninguna demora, cortapisa ni caución en absoluto y sin ningún reembolso ni rescat ${ }^{13}$ en absoluto, sino sólo a sus expensas totalmente.

Y si, Dios no lo quiera, el citado Mošeh se demorara o pusiera trabas a darle a la citada Dueña el apropiado documento legal mencionado, tal y como se ha mencionado, en el plazo de tiempo /4/ citado, se obliga con su persona y bienes, con qinyán íntegro desde ahora, a pagar de multa cien florines de oro, de curso en Aragón y de peso íntegro, la mitad para cualquier rey o reina, gobernante o funcionario gubernamental ante quien presente reclamación la citada Dueña, o sus representantes, contra el citado Mošeh por causa de su transgresión de lo que está escrito en este documento de obligación y sometimiento, y la otra mitad para la mencionada Dueña o sus representantes; y sea pagada la multa o no /5/ pagada, será y quedará este documento de obligación y sometimiento en su validez y su vigor; y todos los gastos, perjuicios y pérdidas que le sobrevinieren a la mencionada Dueña, o a sus representantes, por razón de una demora o traba del citado Mošeh en cumplir todo lo mencionado, se obliga con su persona y bienes, con qinyán íntegro desde ahora, a pagarlos todos con abono completo $\mathrm{y}$ total hasta la última moneda.

Además le otorga el citado Mošeh a Dueña, su yěbama /6/ mencionada, y a sus representantes, pleno derecho y facultad completa para presentar una denuncia contra él en el tribunal judío o ante cualquier juez o magistrado, judío o de los demás pueblos, que quieran la citada Dueña o sus representantes; y haya en manos de ese juez o magistrado capacidad y

12 V. nota 8.

${ }^{13}$ En romance en el texto hebreo. 
facultad para forzarlo, oprimirlo y prenderlo y para mantenerlo forzado, oprimido y prendido a expensas de él; y para que no salga de ese estado de aprehensión nunca hasta que complete y cumpla todo lo mencionado arriba.

/7/ Y para mayor solidez del pleno derecho de la citada Dueña y de sus representantes, jura el mencionado Mošeh con juramento por la Torá para conocimiento de Dios, bendito sea, y de la citada Dueña, sin ninguna puerta para liberarse o arrepentirse de él en absoluto, cumplir y completar todo lo escrito arriba y no transgredir ningún punto de ello. $Y$ otorga su confianza el citado Mošeh a la mencionada Dueña y a sus representantes, en todos los asuntos y detalles de este documento y en los gastos según lo mencionado, con confianza $/ 8 /$ total y absoluta, como si fueran los dos testigos apropiados, sin necesidad de ningún juramento ni anatema en absoluto y de ningún juramento por implicación.

La garantía y la carga de todo lo escrito arriba las acepta el citado Mošeh sobre sí y sobre todos sus bienes, muebles e inmuebles, apropiadamente y conforme a la reglamentación de nuestros rabinos, no siendo éste ni un documento meramente formal ni un formulismo documental, con anulación de todo tipo de protestas que haya en el mundo, manifiestas u ocultas, desde su principio hasta su final.

19/ Y tomamos qinyán nosotros, los testigos firmantes abajo, de manos del citado Mošeh, hijo de maestre Yacaqob de Narbona, para Dueña su mencionada yĕbamâ y para sus representantes, sobre todo lo escrito y expresamente declarado arriba, qinyán íntegro desde ahora, en la medida necesaria.

Fue esto el día 12 del mes de adar $2^{\circ}$ del año 5242 de la Creación ( 3 de marzo de 1482), según nuestro cómputo, /10/ en Tudela. ("en», "plazo" y "y para sus representantes", entre líneas; "garantía", tachado.) Y todo es firme y permanente. Mošeh bar Šelomoh, su fin sea para bien, Hasaní. Mošeh bar Aharón, su memoria sea bendita, ben Çeda. 


\section{RESUMEN}

Entre los documentos hebreos hallados en el Archivo Municipal de Tudela hace 10 años, figura, en un apéndice a una $K e ̈ t u ̂ b b \hat{a}$, el documento que aquí se publica, por el cual un posible futuro yabam, en el momento de la boda de su hermano, se compromete a otorgar la halisâ a la yěbamâ cuando se diera el caso. No era esto habitual en España, pero sí en Francia, y aunque el documento está fechado en Tudela, el yabam, Mošeh de Narbona, y su familia eran de origen francés.

\section{SUMMARY}

Among the Hebrew documents that have been found at the Tudela Municipal Archives ten years ago, we can find in an appendix to a $K \ddot{e} t u \hat{b} b \vec{a}$, the document that is published here, according to which a possible future yabam takes the engagement, at his brother's wedding, to confer the halisâ to the yěbamâ whenever the case arrives. This practice was not usual in Spain, but it was in France, and, although the document was dated at Tudela, the yabam, Mosheh of Narbonne, and his family were of Frech origin. 